\title{
MISCELÂNIA DESCOLADA OU GENTRIFICATION?
}

\author{
Baixo Augusta - São Paulo ${ }^{1}$
}

\section{EDGY MISCELLANEA OR GENTRIFICATION? \\ Baixo Augusta - Sao Paulo}

\author{
Beatriz Salgado Cardoso de Oliveira* \\ Ana Lúcia de Castro ${ }^{* *}$
}

\begin{abstract}
Resumo
A partir de um mapeamento histórico da rua Augusta, na cidade de São Paulo (Brasil), buscamos discutir a (in) adequação do conceito de gentrification para a compreensão de recentes transformações paisagísticas ocorridas na porção central da rua, conhecida como "Baixo Augusta”. Em meados da década de 2000, observa-se na região dois fenômenos característicos do processo de gentrification. Todavia peculiaridades das dinâmicas urbanas no Baixo Augusta nos fazem problematizar a "aplicação" direta desse conceito em nosso caso de estudo. Argumentamos que sua operacionalização em realidades urbanas distantes de sua origem anglo-saxã, pode acarretar uma espécie de violência epistêmica (SPIVAK, 1988). Como alternativa de escape a esse tipo de armadilha epistemológica, sugerimos a prática etnográfica como empreendimento intelectual que coloca em constante relação o teórico e o empírico e busca construir interpretações de realidades locais em articulação com processos estruturais, de escala global.
\end{abstract}

Palavras-chave: Cidades. Gentrification. Violência epistêmica. Etnografia urbana.

\begin{abstract}
Based on a historical mapping of Rua Augusta, in São Paulo city (Brazil), we seek to discuss the (in)adequacy of the concept of gentrification to understand recent landscape changes that have occurred in the central portion of the street, known as "Baixo Augusta". In the mid-2000s, two characteristic phenomena of gentrification could be observed. However, due to peculiarities of the urban dynamics in Baixo Augusta we question the direct "application" of the gentrification concept in our case study. In this sense, we argue that its operationalization in urban realities far from its Anglo-Saxon origin, can lead to a kind of epistemic violence (SPIVAK, 1988). In order to escape this type of epistemological trap, we suggest that the treatment of the urban dynamics of Baixo Augusta occurs through ethnographic practice, as an intellectual enterprise that places the theoretical and the empirical in constant relationship and pursuit to build interpretations of local realities in articulation with structural processes of global scale.
\end{abstract}

Keywords: Cities. Gentrification. Epistemic violence. Urban Ethnograpy.

\section{Introdução}

A rua Augusta é, sem dúvida, umas das regiões mais conhecidas da cidade de São Paulo. Inaugurada em 1897 (conforme consta no Dicionário de Ruas do site da Prefeitura de São Paulo), sofreu muitas transformações ao longo de sua história. Hoje, é especialmente conhecida

\footnotetext{
1 Este artigo é um subproduto da pesquisa "Para além da distinção: gostos, práticas culturais e classe em São Paulo", desenvolvida com o apoio da Fundação de Amparo à Pesquisa do Estado de São Paulo (Fapesp), à qual registramos nossos agradecimentos.

* Doutoranda do Programa de Pós-Graduação em Ciências Sociais Unesp - FCLAr. E-mail: beatrizsalgado.co@ gmail.com

** Professora livre-docente da Unesp - FCLAr. E-mail: castroanalucia75@gmail.com
} 
por comportar o "Baixo Augusta", parte importante do circuito (MAGNANI, 2002) ${ }^{2}$ de lazer jovem de São Paulo, que abarca a região entre a Avenida Paulista e o centro da cidade. Em contrapartida, o outro lado da rua Augusta é comumente chamado de "Jardins", região mais voltada ao comércio, que comporta parte do circuito de compras de luxo da capital, cuja principal referência é a rua Oscar Freire.

Essa divisão da Augusta em duas regiões distintas não consta no mapa geopolítico da cidade, e pode-se dizer que foi construída socialmente, com observância de seus frequentadores às transformações da via ao longo do tempo. ${ }^{3}$

Em geral, os estudos sobre e na rua Augusta a descrevem por meio de suas "fases", uma maneira de organizar histórica e socialmente as transformações ocorridas nessa região paulistana desde a década de 1930. Na maior parte dos casos, há referência a três fases distintas. A primeira, denominada "gloriosa", compreende a primeira metade do século XX, aproximadamente entre 1900 e 1950, período no qual a rua Augusta comportava as lojas e cafés mais elegantes da cidade (RAGAZZO, 2005; DINES, 2011) e, por isso, era frequentada principalmente pela elite paulistana. A segunda fase, entre 1960 e 1990, é vista como período de degradação da rua, momento no qual um duplo processo, de ascensão e decadência da avenida Paulista como polo econômico da cidade, impacta profundamente a rua Augusta, em especial sua região central, cujas paisagens passam a ser marcadas pela degradação de infraestrutura, precariedade dos serviços de transporte público e pelo estabelecimento de pontos de prostituição.

A partir da década de 2000, indica-se um processo de "revitalização" ou de "renovação" da rua Augusta (ARRUDA, 2016; DINES, 2011; MENDES, 2014; PISSARDO, 2013), influenciado por políticas voltadas ao centro da cidade, pelo investimento no transporte público e pelo surgimento de uma série de estabelecimentos voltados ao lazer, como espaços culturais, cinemas, casas noturnas e bares. Naquele período, argumenta-se que a rua é ressignificada e adentra uma fase "descolada", consolidando-se como importante mancha de lazer da cidade de São Paulo, especialmente para o público jovem. Mais recentemente, o noticiário aponta que os bairros Cerqueira César e Consolação, onde estão localizadas a região dos Jardins e do Baixo Augusta, foram campeões de valorização do metro quadrado na cidade (YURI, 2016, n.p.), cujo valor, entre 2006 e 2017 , teria saltado de $\mathrm{R} \$ 3.300,00$ para $\mathrm{R} \$ 10.000,00^{4}$.

\footnotetext{
2 Utilizamos aqui os conceitos de "circuito" e de "mancha" de Magnani (2002). Por "circuito", entende-se uma "categoria que descreve o exercício de uma prática ou a oferta de determinado serviço por meio de estabelecimentos, equipamentos e espaços que não mantêm entre si uma relação de contiguidade espacial" (MAGNANI, 2002, p. 23); e por "mancha", uma categoria que se refere a "áreas contíguas do espaço urbano dotadas de equipamentos que marcam seus limites e viabilizam (...) uma atividade ou prática predominante" (MAGNANI, 2002, p. 21).

3 É possível notar a adoção dos termos "Baixo Augusta" e "Jardins" em reportagens e noticiários sobre a rua Augusta, websites oficiais de turismo da cidade de São Paulo (CIDADE DE SÃO PAULO, 2019) e, inclusive, nos mapas da plataforma Google Maps.

4 A fonte não explicita se o novo valor corresponde a uma média ou ao valor do metro quadrado das novas construções. Ademais, os valores variam também de acordo com o perfil e o tamanho dos imóveis. De qualquer maneira, segundo o portal Proprietário Direto (2020), o valor médio do metro quadrado no bairro da Consolação é de R\$ 9.870 (com base nos imóveis anunciados no site).
} 
Esse cenário de "renovação" do Baixo Augusta e sua suposta ressignificação, combinada ao boom imobiliário e à valorização do solo, podem ser indicativos de um processo de gentrification ou enobrecimento ${ }^{5}$ da região. Não obstante, certas características da atual paisagem da região do Baixo Augusta parecem resistir a um enquadramento nos modelos tradicionais desse tipo de transformação urbana, como veremos adiante.

Isto posto, este artigo se propõe a problematizar a atual paisagem da parte baixa da Augusta a partir da apresentação de um breve histórico das transformações da rua, que dá contornos mais positivos a sua fase de "degradação" e localiza nela o ponto inicial da constituição do Baixo Augusta como mancha de lazer de São Paulo. Argumentamos que a ressignificação do Baixo Augusta não é apenas consequência do deslocamento de capital privado e/ou público para a região, ou seja, da ação exclusiva de empreendedores, construtoras e/ou poder público; há de se considerar um pool de agentes, que (res)significam o Baixo Augusta pelos usos que fazem da região e de seus estabelecimentos, dando-lhe sua atual "identidade", marcada pelo signo da "diversidade" de estilos, configurando uma espécie de miscelânea.

Finalmente, tais especificidades paisagísticas do Baixo Augusta nos compelem a problematizar o suposto processo de enobrecimento da via - tratar-se-ia, de fato, de uma mudança no status social da região? Seria o conceito de gentrification o mais adequado para o tratamento dessa dinâmica urbana?

\section{Histórico: para muito além da degradação}

A segunda fase da rua, entre 1960 e 1990, é usualmente relacionada a uma imagem de degradação (ARRUDA, 2016; DINES, 2011; PISSARDO, 2013; RAGAZZO, 2005), porém, ao mesmo tempo, traz consigo os processos que preambulam a configuração da atual paisagem da via.

Nessa fase, importante notar o impacto, na Augusta, de processos ocorridos na Avenida Paulista. Na década de 1970, a avenida paulistana passa a sediar escritórios de grandes empresas, ganhando "centralidade comercial e financeira da cidade" (PISSARDO, 2013, p. 129). Os efeitos na Augusta são claros: seus terrenos mais próximos à Paulista serviram para a construção de prédios comerciais e, mais tarde, sua parte central recebeu um grande contingente de hotéis, que não apenas abrigam executivos e funcionários dos escritórios, mas cujas estruturas de lazer tornam-se importantes referências na vida noturna da região. Hotéis de luxo, como o Ceasar Park Hotel e o Hotel Ca'D’Oro, contavam com bares, restaurantes e salões de eventos, frequentados pela elite paulistana e pelos executivos das cercanias. Nesse momento, a "fase gloriosa" da Augusta vai ganhando outros ares. Os escritórios da Paulista trazem um novo público para a região, e práticas como o lazer após o trabalho, o famoso "happy hour", começam a caracterizar sua vida noturna.

5 Adotamos como tradução de "gentrification" o termo "enobrecimento", de acordo com as colocações de Rubino (2009). A terminologia será esmiuçada ao longo do artigo. 
Mais tarde, na década de 1980, o fácil acesso à região e seu grande contingente de hotéis e de hóspedes passam a atrair "garotas de programa, travestis e cafetões" (ARRUDA, 2016, p. 38), que atuavam na parte baixa da rua, tanto no trottoir como nos "inferninhos", "casas de massagem" e American Bars que surgiam. Essa aglomeração de estabelecimentos voltados à prostituição favorece a emergência de hotéis menores e de maior rotatividade, que se fortalecem com a nova clientela (PISSARDO, 2013). Mais tarde, na passagem dos anos 1980 para os 1990, transformações na avenida Paulista concorrerão, novamente, para mudanças na Augusta. Atraídos por prédios com arquitetura moderna e alta tecnologia na avenida Berrini e proximidades, os escritórios de grandes empresas começam a deixar o centro paulista, e tornam-se mais visíveis os primeiros sinais de deterioração da região (PISSARDO, 2013; FRÚGOLI JR., 2001).

Evidentemente, a evasão gera consequências imediatas no mercado hoteleiro da Augusta. Somam-se a isso a proliferação dos "inferninhos", os problemas de infraestrutura e transporte da região e a crise econômica e social que vivia o Brasil como um todo. Esses fatores corroboram a imagem de "degradação" da rua, fortalecida pela mídia e apropriada inclusive em representações artísticas (PISSARDO, 2013, p. 142).

Porém, é válido argumentar que essa imagem de "degradação" é uma caracterização gestada fora da realidade dos "nativos" da via - frequentadores, trabalhadores e moradores da Augusta à época. A negatividade do termo não pode traduzir como um todo as dinâmicas sociais que lá se desenvolviam. Ademais, também não é possível afirmar que houve, verdadeiramente, uma nova e homogênea ocupação da Augusta, ou que dela a elite da fase "gloriosa" evadiu completamente. Como comenta Arruda, mesmo que os usos da rua tenham sido alterados, "membros da elite e do proletariado continuavam a ocupá-la e a dividir o mesmo espaço. Só que, neste período, essa interação era proibida e escondida" (2016, p. 38). Assim, no período da década de 1990, e não a partir dos anos 2000, é que a rua Augusta ganhava os ares de "diversidade" que hoje lhes são tão característicos. Um comentário de Massimo Canevacci, de 1993, reforça nosso argumento:

[...] tudo é conjunto, justaposição mistura. Passa-se de maneira absolutamente normal e contígua de famosos hotéis cinco estrelas, que têm as melhores cozinhas da cidade, a casas meio arruinadas, a pequenos palacetes nos quais se anunciam as aventuras e os tabus mais promíscuos [...]. E ao seu lado [...] escolas elementares ou médicas que, quando fecham, à noitinha, fazem com que o inocente público de suas estudantes misture-se na rua com o das mocinhas prostitutas também de sua idade [...] (CANEVACCI, 1993, p. 196).

É possível notar que essa fase de suposta “degradação" é extremamente dinâmica e não implica o desaparecimento ou substituição de certos equipamentos ou práticas culturais por outras, tampouco uma mudança radical ou uma homogeneização de público. Como

6 Pissardo cita uma série de representações artísticas que mobilizaram o imaginário de "degradação" da rua Augusta, "o universo do submundo e da ilegalidade”. Para mais referências, ver Pissardo (2013, p. 142-143). 
procuraremos evidenciar na próxima seção, essa "justaposição" e "mistura” de públicos, práticas culturais e equipamentos, é que caracterizará com mais força a "renovação" do Baixo Augusta.

\section{Revitalização}

O enfraquecimento do Centro Paulista teve grande impacto nas transformações de paisagem da Augusta, porém, ao mesmo tempo, outros estabelecimentos de peso, inaugurados no final da década de 1960, como o Masp, a Faculdade Cásper Líbero e o Conjunto Nacional (ARRUDA, 2016), auxiliam na permanência da rua como local de lazer e cultura, especialmente para o público interessado em comunicação e arte, frequentador dos cinemas, teatros e da vida noturna da via.

Ressalte-se que, ainda no período de "degradação", imóveis desvalorizados pela presença dos "inferninhos" e dos pontos de prostituição atraem jovens estudantes que "viviam a Augusta da noite, faziam amizade com as prostitutas e bebiam até mais tarde nos bares da região" (ARRUDA, 2016, pp. 42-43). Esse novo grupo de moradores e frequentadores da via certamente influenciaram o surgimento de uma série de baladas "underground", que funcionavam nos porões de estabelecimentos comerciais. Consolida-se, nesse momento, um novo circuito de música alternativa e rock'n'roll, que passa a caracterizar e dar contornos mais nítidos à região que viria a ser conhecida como "Baixo Augusta" (ARRUDA, 2016, p. 40; PISSARDO, 2013) ${ }^{7}$.

Ainda nos anos 1990, inicia-se uma discussão sobre a requalificação de áreas centrais da cidade em processo de deterioração, com impactos indiretos para a rua Augusta, que é alvo de algumas ações "visando sua requalificação e valorização imobiliária” (PISSARDO, 2013, p. 179). $\mathrm{Na}$ esteira desse processo, assiste-se à evasão das classes populares e grupos marginalizados da região e à chegada de moradores e frequentadores das classes médias à praça Roosevelt ${ }^{8}$. Fronteira entre o centro da cidade e a rua Augusta, a Roosevelt renovada contribuirá para a "nova" imagem do Baixo Augusta como local "descolado" de lazer para o público jovem.

Esse momento de deslocamento do capital público para o centro da cidade é fortemente acompanhado, no caso do Baixo Augusta, pelo investimento do capital privado. De fato, a maioria dos estudos apontam como símbolo da sua fase de "revitalização" a inauguração de empreendimentos comerciais como a casa noturna "Vegas" (rua Augusta, 765), dos empresários Facundo Guerra e José Tibiriça Martins, em 2005, e também o Espaço de Cinema Unibanco.

\footnotetext{
7 Pissardo ressalta que as casas noturnas da rua Augusta possuíam perfis diferentes de acordo com o "lado" em que estavam. Na região dos Jardins, esses estabelecimentos eram, em geral, voltados para um público de maior poder aquisitivo e tocavam música eletrônica. Já o lado central da Augusta comportava casas noturnas de preços mais acessíveis, nas quais predominava o rock'n'roll. (PISSARDO, 2013, p. 154-155).

8 A renovação da praça Roosevelt é iniciada de fato apenas em 2010. São notáveis as ações policiais para a exclusão de grupos marginalizados da região, que poderíamos categorizar como ações de "higienização". Com a exclusão de tais grupos e a vinda de camadas da classe média, é possível notar um processo de enobrecimento da região, nos termos de Silvana Rubino (2009) (PISSARDO, 2013, p. 186).
} 
Outros tantos novos estabelecimentos de lazer são inaugurados ao longo da década de 2000, entre bares, restaurantes, baladas etc., frequentados, majoritariamente, por um público jovem bastante variado, que compõe uma "cena noturna" única, "cujos personagens convivem no mesmo espaço com mulheres da noite, dançarinas de strip-tease e vendedores ambulantes" (DINES, 2011, p. 1). O Baixo Augusta passa a ser "a rua que interessa", parte de um "circuito de jovens" (MAGNANI, 1993; 2005), por oferecer desde os pontos de encontro, como a saída do metrô Consolação e as escadarias do Banco Safra, até os bares para o "esquenta", restaurantes, baladas dos mais variados tipos e os fast-foods do "after party".

Interessante notar que esses novos empreendimentos ressignificam, em suas propostas e design, as imagens da fase "degradação" da rua. Como observa Pissardo (2013), a decoração e as festas promovidas pelas novas casas noturnas que são inauguradas no Baixo Augusta, na esteira do Clube Vegas, ajudaram a "glamourizar' o universo e a estética da prostituição", "através de decoração exagerada, romantizada ou vulgar dos clubes, recorrendo a cores fortes, dourados, veludos, almofadas, lustres de cristal, etc., elementos que procuravam refletir a atmosfera dos prostíbulos (PISSARDO, 2013, p. 143) ${ }^{9}$. O Beat Club (rua Augusta, 625), por exemplo, contava com esse tipo de "atmosfera":

[...] a experiente hostess Adriana Recchi, a promoter Vivi Flaksbaum e o empresário Gigio usam de suas experiências baladeiras para montar o Beat Club [...] "Escolhemos um antigo inferninho de três andares e demos um ar de cabaré", conta Adriana (GIOVANELLI, 2011, n.p.).

Nota-se, assim, que a fase caracterizada por autores como aquela de "degradação" da Augusta forneceu, na verdade, o arcabouço de imagens e sentidos que foram apropriados e ressignificados na "nova fase descolada" da rua. É possível, então, falar de degradação da Augusta apenas no que tange à infraestrutura - prédios abandonados, transporte problemático, calçadas esburacadas. Todavia, no que refere à sociabilidade, a ideia de "degradação" não convém - é justamente a "mistura" social desse período que caracterizará a Augusta "renovada" e "descolada" dos anos 2000, descrita como local de diversidade social e cultural, como é possível observar nas narrativas dos jovens entrevistados por Dines (2011):

Por exemplo, Franz considera que "a rua é o mais interessante. Gosto, quanto mais misturado melhor. As pessoas ficam mais abertas, mais livres." Ou, como Jessica considera "gosto da situação, as pessoas se socializam, pedem isqueiro, as pessoas são

\footnotetext{
9 Clubes, como o Studio SP (Augusta, 591), apresentavam atmosfera "underground" e artística, com exposições de arte e shows de músicos brasileiros de vanguarda (STUDIO SP anuncia que encerra atividades neste mês de abril, 2013). Restaurantes, como o Z Carniceria (Augusta, 934), também apresentavam ar "descolado". Dines comenta: "Apresenta um aspecto bem particular (...) procura lembrar o açougue que havia lá. Já na porta, visualiza-se esta diferença, pois as maçanetas são dois cutelos. Nas vitrines, ao lado da porta, vemos caveirinhas mexicanas e também correntes. Dentro do ambiente, foram mantidos os azulejos azul piscina na parede, há reboco exposto e os garçons usam aventais como os de um açougue. Nas paredes há ganchos pendurados de prender carne, caveira de touro, além de retratos, uma espingarda, dentre outras quinquilharias" (DINES, 2011, p. 4).
} 
bem abertas. Lá, dá para ser outra pessoa - me libertar, sair do habitual. [...]. Também considera como outros jovens entrevistados, que há "diversidade sexual, mundos diferentes, sem preconceitos." (DINES, 2011, p. 6).

Na primeira década de 2000, a "renovação" da rua Augusta é marcada por um boom imobiliário, resultado de um processo de rent-gap, caracterizado por "uma alternância de investimento e desinvestimento, na qual esse último produz, em valores de terra urbana e propriedades construídas, a possibilidade do reinvestimento" (RUBINO, 2009, p. 28). No caso da rua Augusta, pode-se dizer que há o investimento em sua fase "gloriosa", o desinvestimento em sua fase de degradação da infraestrutura e, finalmente, um processo de reinvestimento caracterizado por uma série de fatores intimamente interligados. O desenvolvimento da mancha de lazer na Augusta faz com que a região passe a ser procurada enquanto espaço de moradia "por um público jovem já frequentador do lazer na rua e que gostaria de ter acesso fácil às opções de lazer e cultura" (PISSARDO, 2013, p. 188). O aumento da procura por moradia na região e a própria consolidação da mancha de lazer têm como consequência o incremento nos preços dos terrenos e no valor do aluguel, o que impulsionará sua aquisição por grandes incorporadoras. Mesmo os novos estabelecimentos que deram à Augusta seu ar "descolado" sofrem com esse processo de valorização. Isso acontece, por exemplo, com o clube Vegas, que encerrou suas atividades em $2012^{10}$.

Esse processo é facilmente notado na estética da rua. A Figura 1 aponta vinte novos empreendimentos imobiliários construídos ou em construção na rua Augusta, nos últimos dez anos. A maior concentração desses prédios está na parte baixa da via. Alguns dos empreendimentos se destacam ${ }^{11}$ pelo tamanho. Por exemplo, a nova construção que hoje abriga os revitalizados hotel e restaurante "Ca'd'Oro" foi erguida em modelo misto e comporta duas torres de quase 120 metros (TRINDADE, 2011) ${ }^{12}$.

10 Como comenta um de seus antigos sócios, Facundo Guerra: "O galpão onde o mesmo [Vegas] se encontra recebeu uma proposta de compra milionária para ali ser montado um empreendimento imobiliário [...]. Como inquilinos, nunca poderíamos cobrir a oferta que o imóvel recebeu, e batalhamos até o último segundo. Mas nesta segunda-feira resolvemos jogar a toalha" (SAMPAIO, 2012, n.p.).

11 O mapa foi desenvolvido a partir de um levantamento de dados e imagens, por meio de trabalho de campo e pesquisa na internet, conduzido entre o segundo semestre de 2017 e o primeiro semestre de 2018 .

12 Também se destaca o prédio residencial "Capital Augusta”, localizado na esquina com a rua Dona Antônia de Queirós, com "ampla área de lazer", que tem desde "espaço café com wi-fi" até "SPA" (RUA AUGUSTA, em São Paulo, valoriza e atrai lançamentos imobiliários, 2011, n.p.). 
Figura 1 - Mapa desenvolvido na plataforma "My Maps” da Google (mai. 2017/ago. 2018).

Os pontos azuis mostram empreendimentos identificados ao longo da investigação.

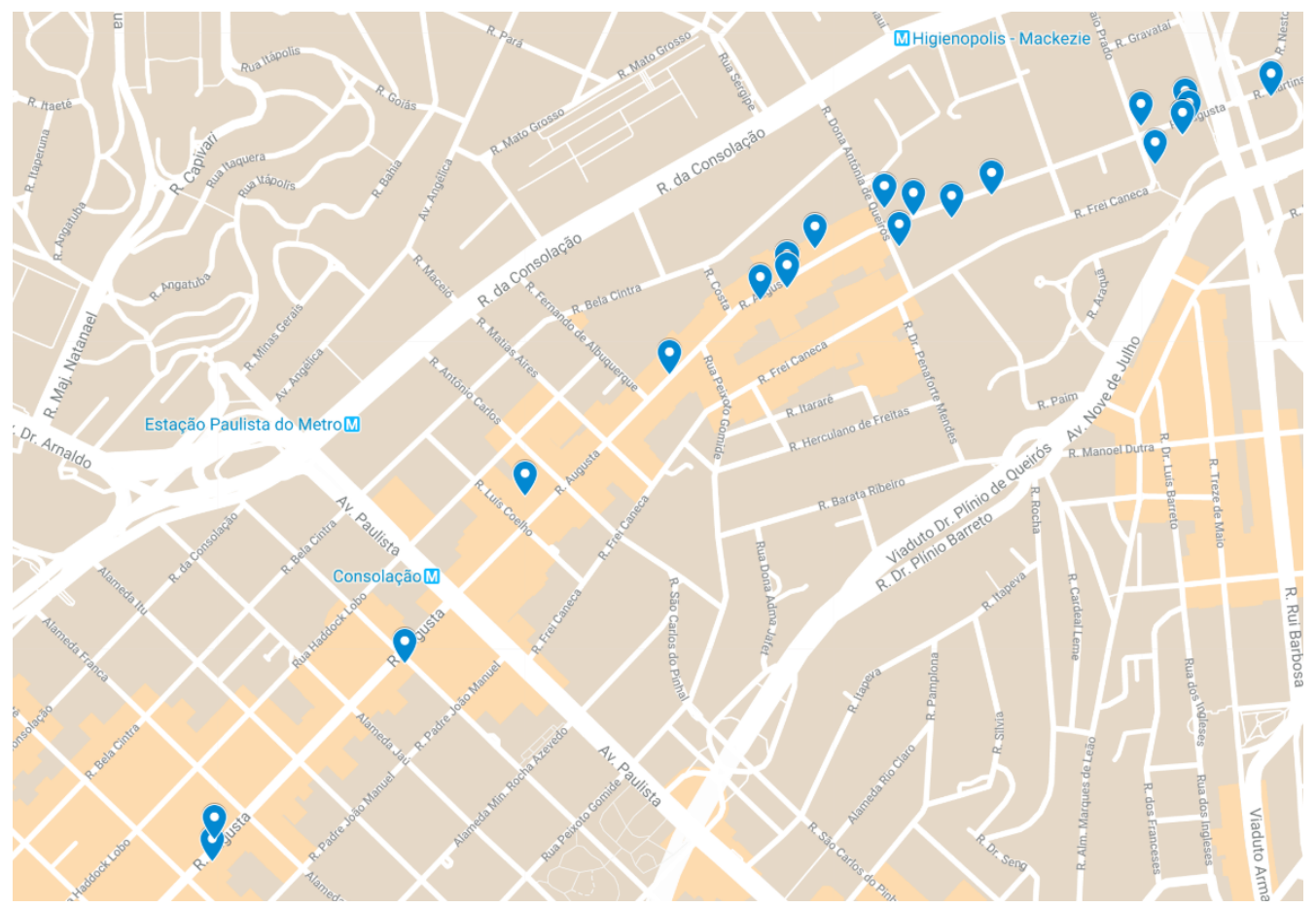

A estética moderna dos novos edifícios contrasta com a paisagem mais antiga da rua. Apesar de sua localização privilegiada em relação à aglomeração de equipamentos culturais, muitas dessas novas torres residenciais contam, paradoxalmente, com grandes áreas voltadas ao lazer e são circundadas por altos muros e gradis. Algumas delas, como o "Capital Augusta", foram construídas de forma que suas portarias estivessem localizadas nas ruas perpendiculares, enquanto que sua fronteira com a rua Augusta fosse totalmente murada (PISSARDO, 2013, p. 189). Ressalte-se também que muitas dessas construções estão bastante próximas da região do Baixo Augusta, que comporta o que sobrou de seus "inferninhos" e stripclubs.

Diante deste cenário, o noticiário mais recente sobre a rua Augusta faz amplo uso do termo "gentrificação" para caracterizar suas transformações ${ }^{13}$. Por exemplo, em matéria de 2016 no site da Folha de São Paulo, o Baixo Augusta é caracterizado como "Garoto-propaganda da transformação do centro" que passa atualmente pelo fenômeno da gentrificação. É quando a mudança urbana é acompanhada da chegada de novos moradores, com maior poder aquisitivo"” (YURI, 2016, n.p.). Ou ainda, a matéria do website do jornal "Nexo" aponta: "Andar pela [...] que ficou conhecida como o Baixo Augusta, revela uma sucessão de novos empreendimentos

13 Para exemplos de como as dinâmicas urbanas do Baixo Augusta são tratadas na mídia ver Freire (2019), FRB (2014), Rocha (2015), Yuri (2016) e Angiolillo (2019). 
imobiliários [...] Esse processo [...] no qual residências e comércio são substituídos por novos ocupantes de renda e preços mais altos, é chamado gentrificação" (ROCHA, 2015, n.p.).

A popularização do termo é notável, e mesmo a literatura acadêmica corrobora essa visão, afirmando haver de fato a gentrificação na rua Augusta ou sondando sua possibilidade (PUCCINELLI, 2017; PISSARDO, 2013; MENDES, 2014; VEGA, 2008). Por exemplo, o estudo de Pissardo (2013) argumenta que ocorre na rua Augusta uma "gentrificação" mascarada pelas atividades e equipamentos que constituem sua mancha de lazer. Já o estudo de Veja (2008), um pouco anterior, flerta com a possibilidade de afirmar a ocorrência de tal processo. Mas, afinal, trata-se mesmo de gentrificação?

\section{Gentrification - uma breve revisão do termo}

O termo gentrification tem origem bastante distante da realidade das cidades brasileiras. Cunhado pela socióloga Ruth Glass (1964), faz referência a uma crise de suburbanização em Londres, quando bairros antes habitados pelas classes trabalhadoras são "invadidos" pelas classes médias. Nesse processo, prédios históricos são revalorizados e os custos de vida e de moradia na região são inflacionados, "até que a maioria dos ocupantes trabalhadores originais são deslocados, e todo o caráter social do bairro é alterado" (GLASS, 1964, p. xvii-xix, grifo nosso). Entendemos essa como a fórmula "clássica" do processo de gentrification. É ela que, duas décadas mais tarde, entre 1980 e 1990, será redefinida em um novo debate, agora de escala global, que transformará a própria natureza do termo - o que era antes termo descritivo, passa a ser um conceito analítico (RUBINO, 2009, p. 26).

Esse é um aspecto importante no desenvolvimento dos estudos sobre gentrification, pois, ao ganhar caráter de conceito analítico, extrapola os contornos de sua fórmula clássica e é apropriado por uma série de autores a fim de analisar diferentes realidades urbanas ao redor do globo - e não apenas norte-americanas ou anglo-saxãs. Nos limites de um artigo, não seria possível analisar as diferentes abordagens em torno desse conceito que, ora se mostram mais fiéis à ideia originária, ora a transformam e a adaptam a outras realidades urbanas. Preferimos assim elencar os principais debates em torno da natureza desse conceito: a) preservação versus demolição/construção; b) forças econômicas versus forças culturais; c) habitação versus usos do espaço - ou "gentrificação de convívio", como propõe Gaspar (2010)14.

Em primeiro lugar, o processo descrito por Ruth Glass não é de alteração apenas no espaço construído, mas também na percepção que se tem do bairro, no que diz respeito a seu novo status - um ambiente antes degradado é revestido de charme e distinção (RUBINO, 2009, p. 26). Nesse sentido, vale a referência a uma gama de estudos acadêmicos brasileiros que analisa projetos de

14 Não é nossa intenção oferecer aqui uma revisão bibliográfica sobre esta temática, aliás, realizada já por muitos autores (RUBINO, 2009; GASPAR, 2010; LEITE, 2007). Procuramos apenas pontuar as características mais marcantes do conceito de gentrification, a fim de problematizar o caso do Baixo Augusta. 
"revitalização" de centros históricos, como por exemplo a pesquisa de Leite, em Recife (2007), de Scouguglia, em João Pessoa (2004), ou de Botelho, em Fortaleza, São Luís e Vitória (2005). Nestes casos, é notória a relação entre patrimônio e tradição, por um lado, e consumo, por outro. Leite aponta que no processo de gentrification, a cidade é reinventada "como vitrine do consumo da tradição pelo city-marketing e suas políticas contemporâneas de patrimônio cultural", num movimento que transforma "os significados de uma localidade histórica em um segmento de mercado" (LEITE, 2007, p. 18-19). Assim, o processo traz repercussões importantes para os habitantes originais do local. Como ressalta Mira, “[...] nestes projetos de "revitalização" urbana onde a atração é a cultura local ou regional, entra a "cultura popular", saem as classes populares" (MIRA, 2016, p. 128).

Por outro lado, o debate sobre gentrification também gira em torno da possibilidade de relacionar o conceito analítico a movimentos de transformação do espaço construídos não apenas no que tange à preservação e à valorização de prédios históricos, mas também à sua demolição e/ou construção, em seu lugar, de novos edifícios de arquitetura moderna. Rubino volta-se para a própria realidade brasileira a fim de questionar esse tipo de transformação do espaço físico. A autora nos dá como exemplo os casos do bairro paulistano da Mooca e da área ferroviária da cidade de Campinas e nota que, em tais regiões, elege-se apenas um edifício, ou um conjunto deles, para que seja "culturalizado" e transformado em equipamento cultural, "botando-se abaixo" o restante. Tal cenário, para a autora, não caracteriza a gentrification, ao menos de acordo com sua conceituação clássica (RUBINO, 2009, p. 29).

O segundo debate aqui ressaltado dá-se em torno da natureza dos agentes da gentrification. Por um lado, autores como Neil Smith (2000) argumentam que a gentrification se dá, exclusivamente, pela volta do capital aos centros das cidades. Assim, os agentes desse processo seriam apenas construtores, empreendedores, poder público, etc., e as forças econômicas predominariam absolutamente sobre as culturais. Nessa perspectiva, os novos habitantes da região gentrificada não são agentes, mas são passivos em relação à força do capital (RUBINO, 2009, p. 28). Já outras abordagens, como por exemplo a de Sharon Zukin (1989), agregam outros atores sociais ao processo. Segundo Rubino (2009), essas abordagens têm, em geral, bases etnográficas, e analisam a produção da cidade por um pool de atores, e não apenas sua reprodução.

Evidentemente, a abordagem economicista apresenta sérios problemas, e o próprio caso paulistano pode evidenciá-los. Os estudos de Frúgoli e Sklair (2009) apontam como as tentativas do poder público e da iniciativa privada de fazer da Nova Luz um bairro cultural não foram suficientes para atrair novos tipos de frequentadores que de fato vivenciassem a região como um todo e não apenas seus principais equipamentos culturais, como a Pinacoteca e a Sala São Paulo (FRÚGOLI; SKLAIR, 2009; GASPAR, 2010). Segundo os autores, 


\begin{abstract}
A [...] Sala São Paulo, por exemplo, atrai uma certa população às noites, que utiliza, quase que na totalidade, seus carros para locomoção, deixando-os no estacionamento do próprio prédio. A Pinacoteca, por sua vez, atrai um número considerável de visitantes, mas a grande maioria tem acesso à instituição através do metrô, com uma das saídas situadas logo à sua frente, sem qualquer necessidade de interação com o resto do bairro. Não se pode negar, então, que tenha havido mudança na população que frequenta circunstancial ou pontualmente o bairro (...), mas isso não configura, a princípio, uma mudança na vida pública do bairro em questão (FRÚGOLI; SKLAIR, 2009, p. 129).
\end{abstract}

Nota-se que o debate sobre a natureza dos agentes da gentrification é intimamente ligado àquele sobre habitação e usos do espaço. Em sua "fórmula clássica", as regiões da gentrification recebem um novo contingente de moradores e não apenas de frequentadores de classes mais elevadas do que as originais. Porém, quando a gentrification passa ao status de conceito-analítico e é pensada globalmente por pesquisadores, a hipótese "baseada em frequência e consumo" torna-se válida. Não obstante ela depende da averiguação "de que os espaços públicos do bairro vêm sendo ocupados por novos grupos", de maneira que esses vivenciem de fato a região e não apenas utilizem de maneira pontual seus equipamentos culturais (FRÚGOLI; SKLAIR, 2009, p. 129).

Gaspar (2010) faz referência a estudos de casos latino-americanos de gentrification similares ao da Luz e que esclarecem igualmente este debate. Esses casos demonstram como certos bairros de classes populares passam a ser revestidos de nova "aura" ao ganharem uma diversidade de novos equipamentos culturais, sendo, porém, apenas frequentados por um novo público, advindo das classes médias, e muito pontualmente. Esse é o cenário das transformações em áreas centrais da Cidade do México, estudadas por Hiernaux-Nicolas (2006). Nesse caso, por meio do investimento público e privado, há a "retomada do centro pelas atividades comerciais, de serviço e de lazer, dentre outras, mas principalmente as culturais". Todavia, apesar da frequentação da região pelas classes médias e altas, não há real "vivência" da área, assim como no caso da Luz. Como nota o autor, "os restaurantes e boates só têm sucesso porque adotam o sistema de manobristas [...]. Não se anda no centro à noite, mesmo quando se vai a um concerto no Palácio de Belas Artes (há um estacionamento subterrâneo em frente) ou a um restaurante" (HIERNAUX-NICOLAS, 2006, p. 254, grifo nosso).

Não foi nosso objetivo realizar uma revisão bibliográfica sobre o tema da gentrification, já elaborada por outros tantos autores ${ }^{15}$; tampouco procuramos engessar o conceito ao enfatizarmos sua concepção mais "clássica". Com efeito, é inevitável que qualquer conceituação se amplie e se diversifique ao tomar dimensões globais, afastando-se cada vez mais de sua concepção original. Ao mesmo tempo, as diversas facetas do conceito de gentrification e a necessidade de adaptações de suas características, para modelos fora de seu universo de origem, podem evidenciar tanto sua plasticidade como sua fragilidade analítica. Os dois casos latino-americanos citados são 
bons exemplos de como certas dinâmicas urbanas podem apresentar algumas das características da gentrification, mas não sua característica principal: a real mudança de status social do bairro. Resta-nos saber, neste contexto, como caracterizar o caso do Baixo Augusta.

\section{Baixo Augusta: gentrification em debate}

Exploramos agora a possibilidade de analisar as transformações do Baixo Augusta nos termos do debate sobre gentrification. Os recortes geográfico e temporal se justificam por uma série de razões. Ressalte-se, em primeiro lugar, que tanto o boom imobiliário como a fase de "renovação" da Augusta são datados a partir dos anos 2000 e, como demonstramos, têm como preâmbulo um percurso histórico que data da fase de degradação da rua. Em segundo lugar, como mostra a figura 2, os resultados do boom imobiliário são muito mais expressivos na região do Baixo Augusta - dos vinte novos empreendimentos imobiliários, apenas três deles localizam-se na porção dos "Jardins”. Finalmente, os estudos sobre e na rua Augusta apontam uma transformação simbólica especificamente em sua região baixa, sendo que sua outra porção continua a ser caracterizada por um perfil mais comercial.

No que tange à transformação do espaço físico, o caso do Baixo Augusta não se enquadra na ideia de preservação e valorização do patrimônio, mas sim no caso das "novas construções". Os efeitos do boom imobiliário são inegáveis - as novas torres comerciais e residenciais transformaram de forma impactante a estética arquitetônica da via. Mais importante, como notamos ao longo do histórico da rua Augusta, é possível observar que houve de fato o processo de rent-gap, também característico da gentrification. Não obstante, quando adentramos as questões das forças econômicas e culturais, e das mudanças habitacionais e de uso do espaço, o caso do Baixo Augusta começa a se afastar das dinâmicas que o conceito de gentrification abarca.

O ponto principal desse afastamento é o fato da região do Baixo Augusta não ter se modificado em termos de sua principal atividade: o lazer. É salutar, nesta perspectiva, resolver uma problemática temporal. Como já exposto, tanto trabalhos acadêmicos como matérias jornalísticas indicam que o processo de gentrification na Augusta teve como início os anos 2000, que marcam uma nova fase da via, após o período caracterizado como aquele de "degradação". Afirmar que esta nova fase da rua configurou o processo de gentrification implicaria a substituição dos habitantes e/ou dos frequentadores "originais" da região por um novo contingente, de classes mais altas, que ressignificariam o local, conferindo-lhe novo status.

Porém, como procuramos demonstrar, se a região do Baixo Augusta foi ressignificada, isso aconteceu justamente ao longo da "degradação". É quando da desvalorização dos imóveis que a via recebe como moradores os jovens universitários que incentivam a abertura de empreendimentos comerciais na parte baixa da Augusta, como as casas noturnas underground, que caracterizam um certo estilo de vida. Essas passam a coexistir com os "inferninhos" e com o circuito de cinema alternativo e teatro, garantindo a frequentação da rua para fins de lazer. 
O imaginário atual da via, que tem em seu bojo a ideia de diversidade - como aponta o texto de Canevacci (1993), as narrativas dos jovens frequentadores da Augusta (DINES, 2011) e até mesmo o design das "novas" casas noturnas e bares - é tributária justamente da valorização da imagem de "degradação". Não é possível afirmar, então, que houve mudança no status do Baixo Augusta, que permanece como mancha de lazer, frequentada pelos mais variados grupos.

Nesse sentido, é mais apropriado argumentar que, na rua Augusta, existe uma espécie de "conjugação de cronologias espaciais" (FERNANDES, 2009, p. 196). Dito de outra maneira, novas inscrições nas paisagens da via coexistem ou mesmo se justapõem a elementos do passado: antigos "inferninhos" coexistem com as novas torres de apartamentos; lojas da "fase gloriosa" da via resistem a todas suas transformações ${ }^{16}$; o circuito de teatro e cinema transforma-se, mas ainda é presente e característico da Augusta, assim como os bares e baladas, que se adaptam a novas modas ${ }^{17}$ e mantêm o status do Baixo Augusta de importante mancha de lazer jovem de São Paulo.

Não se trata de negar o impacto das transformações causadas pelo rent-gap e pelo boom imobiliário. Certamente, esses processos tiveram repercussões notórias na via. Importantes casas noturnas e bares, como o Clube Vegas, acabaram por fechar as portas, por não conseguir competir com as grandes incorporadoras. Porém novos clubes noturnos, restaurantes e bares continuam a surgir, outros conseguem manter a atividades, e até mesmo resistem ainda alguns strip-clubs em frente a novas torres comerciais e residenciais.

Também se observa uma resistência por parte da população às forças econômicas e às ações das construtoras, como demonstra, por exemplo, o debate em torno do Parque Augusta ${ }^{18}$, ou a própria narrativa de conhecidos empresários da região como Facundo Guerra, que afirmou em relação ao cenário de especulação imobiliária: "Eu vejo com certo ar de tristeza, mas ao mesmo tempo entendo que a rua é viva. É uma especulação barata, em função da arquitetura de péssimo gosto, e cara ao mesmo tempo em função do preço do metro quadrado" (Depoimento de Facundo Guerra, concedido ao R.7, 2013).

A despeito de apresentar algumas características do processo de gentrification, o cenário do Baixo Augusta revela também suas peculiaridades, que incitam uma série de questionamentos: O rent-gap é suficiente para caracterizar a gentrification? A longo prazo, os condomínios e torres muradas alterarão a paisagem simbólica da via, substituindo a mancha de lazer, marcada pela

16 Por exemplo, a loja de chapéus "Plas" (rua Augusta, 724).

17 A título de exemplo, ver a matéria de Moretti, 2019.

18 Localizado em uma área de quase 25 mil metros quadrados, entre a rua Caio Prado e a Marques de Paranaguá, o terreno era propriedade das construtoras Setin e Cyrella e permanecia fechado desde 2013. Em 2015, no aniversário de São Paulo, milhares de pessoas ocuparam o local em "uma mobilização festiva pela liberação da área e sua efetivação integral como parque municipal” (A LUTA, 2015). Com outras formas de mobilização em torno do Parque Augusta, como petições on-line (PETIÇÃO, 2016), a formação do OPA - Organismo Parque Augusta (CONCLI, 2018), etc. -, as construtoras "aceitaram ceder o terreno em troca de títulos que permitem a realização do empreendimento que seria feito no local em outra área” (MELLO, 2020). 
diversidade, por um cenário "enobrecido"19? Ou ainda persistirá a mancha e seus frequentadores, numa espécie de "contra-uso" da região (LEITE, 2007)? Argumentamos que tentar enquadrar o caso do Baixo Augusta no modelo de gentrification pode configurar uma violência epistêmica, no sentido desenvolvido pela crítica pós-colonial e seu desdobramento crítico, autodenominado decolonialismo.

\section{Considerações finais: uma crítica ao conceito de gentrification}

Um dos pressupostos das reflexões desenvolvidas pelos pós-coloniais refere-se à ideia de que os processos de colonização implicaram uma violência e uma dominação não apenas territorial, mas também epistêmica. O fim da situação colonial, representado pela desocupação formal, não implicou o desaparecimento de procedimentos, categorias e tecnologias associados ao domínio colonial, nem o deslocamento da Europa enquanto referência primordial para muitas histórias e geografias pós-coloniais.

Uma das principais contribuições dos autores pós-coloniais reside em sua potente crítica ao eurocentrismo presente nas ciências humanas. Stuart Hall (2016), por exemplo, aponta como elas reproduzem a perspectiva colonial, ao alimentar e legitimar o modelo de representações entre a Europa e o resto do mundo. O autor aponta a dicotomia West/Rest como um dos fundamentos da Sociologia moderna, a qual adota parâmetros, normas e valores encontrados nas sociedades ocidentais como balizas para definição de sociedades modernas e define as sociedades não ocidentais pela ausência ou incompletude, frente ao padrão moderno evidenciado pelas sociedades ocidentais:

Bons exemplos da incorporação pela sociologia moderna do binarismo West/ Rest seriam, para Hall, categorias como patrimonialismo, em Weber, e modo de produção asiático, em Marx, que, de formas distintas, fraseam o movimento interno de sociedades definidas como não ocidentais na gramática implicitamente comparativa que toma as sociedades europeias como padrão (COSTA, 2006).

Nessa mesma linha, Spivak (2010) destaca, como um desdobramento da situação colonial, a violência epistêmica, que desclassifica os conhecimentos e as formas de apreensão do mundo do colonizado, expropriando-lhe a possibilidade da enunciação. Inspirados na crítica foucaultiana à episteme das Ciências Humanas (FOUCAULT, 1999), os autores vinculados à vertente pós-colonial buscam garantir um lugar de fala que valorize e legitime a voz dos sujeitos subalternos, em luta por representação. Nas palavras de Machado:

19 Ressalte-se a tradução de Rubino (2009) para o termo anglo-saxão gentrification - enobrecimento - e não gentrificação. Essa escolha enfatiza a principal característica desta dinâmica urbana: uma transformação simbólica de uma região, de seu status social (RUBINO, 2009, p. 38). 
[...] o que caracterizaria uma situação pós-colonial seria uma relação de insuficiência representacional, ou seja, uma incapacidade crônica dos sujeitos de expor sua própria narrativa sobre os fatos. Grupos subalternos que não têm controle sobre a própria imagem seriam os grupos que vivem em situações pós-coloniais: populações marginalizadas em geral (MACHADO, 2004, p. 20).

Essa discussão parece apropriada para análise acerca da pertinência ou não da noção de gentrification na compreensão das referidas transformações experimentadas pelo Baixo Augusta. Parece-nos que a mobilização dessa noção, neste caso em estudo, produz uma modalidade de violência epistêmica, por inviabilizar os diferentes agentes, suas memórias, representações, significações e modos de uso do espaço ali experimentados nos processos de transformação acima relatados.

Um conjunto de autores latino-americanos vêm desenvolvendo uma nova perspectiva crítica, como desdobramento do pós-colonialismo. Trata-se da proposta decolonial, representada por autores como o sociólogo peruano Aníbal Quijano (2000) e o semiólogo argentino Walter Mignolo (2017). O ponto nevrálgico da perspectiva decolonial refere-se à necessidade de buscar uma crítica ao eurocentrismo que parta da especificidade latino-americana, apontando que as teorias pós-coloniais têm seu contexto de enunciação situado no legado colonialista do imperialismo inglês. Como aponta Walter Mignolo (apud BALLESTRIN, 2013), seria preciso promover um rompimento com a crítica pós-colonial, ainda muito presa aos referenciais teóricos do norte, e construir uma crítica à modernidade e à colonialidade a partir de um ponto de vista da América Latina, que foi a primeira a se submeter à dominação colonial/imperial e moderna e, além disso, guarda relações de subalternidade colonial em relação ao império estadunidense. Modernidade e colonialidade, na perspectiva analítica defendida por Walter Mignolo (2017) são indissociáveis:

[...] a "modernidade" é uma narrativa complexa, cujo ponto de origem foi a Europa, uma narrativa que constrói a civilização ocidental ao celebrar as suas conquistas enquanto esconde, ao mesmo tempo, o seu lado mais escuro, a "colonialidade”. A colonialidade, em outras palavras, é constitutiva da modernidade - não há modernidade sem colonialidade (MIGNOLO, 2017).

Buscamos, na reflexão proposta nos limites deste artigo, vislumbrar uma perspectiva de análise que, "sem jogar a criança com a água do banho", mobilize criticamente a contribuição teórica desenvolvida pelos clássicos em contexto europeu, revestindo-a com pressupostos do debate pós-colonialista, ao assumir uma perspectiva crítica, relacional e não substancialista na operacionalização de ideias e conceitos.

A noção de gentrification é tributária das teorias da modernização, carregando em seu bojo o ideário do progresso, do desenvolvimento, do planejamento e ascetismo. A sua transposição direta para aplicação no contexto da rua Augusta implicaria a reprodução de uma 
postura intelectual que reproduz abordagens eurocêntricas, apoiadas em um arsenal teóricoconceitual produzido pelas autorreferidas Ciências Humanas, em contexto europeu.

A globalização do conceito de gentrification fez com que ele se tornasse lugar comum. Mais ainda, sua recepção pode ter acarretado o apagamento das peculiaridades e das localidades. Como uma das alternativas possíveis para escapar desse recorrente caminho - que acaba por se revelar como armadilha - sugerimos que o tratamento das dinâmicas urbanas do Baixo Augusta, bem como de outras realidades das cidades latino-americanas, parta da prática etnográfica, por seu potencial de desvendar sujeitos ocultos e vozes silenciadas, memórias e experiências não registradas, que passam desapercebidas pelo olhar que busca evidenciar as marcas do tão desejável desenvolvimento modernizante.

Levando em conta as críticas pós-colonial e decolonial expostas, sugerimos ainda um movimento epistemológico que trate a pesquisa etnográfica como esforço intelectual, no sentido geertziano, ou ainda como etnografia-e-teoria, para citar Mariza Peirano (2014). Dito de outro modo, a ideia é a de que os conceitos analíticos não sejam importados ou previamente definidos, mas desenvolvidos ao longo da prática etnográfica, em comunicação constante com a realidade estudada.

A intrínseca relação entre a prática etnográfica e a teoria antropológica já foi reiterada por uma série de autores ${ }^{20}$. Como propõe Mariza Peirano (1995), a história da disciplina antropológica é caracterizada pela busca de visões alternativas à generalização e universalização de conceitos, em sua busca incessante pelo diálogo com o "Outro", visando uma ideia de humanidade construída pelas diferenças. Para a autora, a teoria antropológica se desenvolve vinculada ao conhecimento etnográfico - há um diálogo direto entre teoria acumulada e fatos etnográficos (PEIRANO, 1995).

Além da estruturante relação entre os planos teórico e empírico, a prática etnográfica vem sendo marcada pela forte preocupação com a articulação entre as relações localmente experienciadas e as estruturalmente definidas, em escala global. Desde o que podemos denominar como virada interpretativista, inaugurada por Geertz (2008), os antropólogos vêm se debruçando sobre a questão, buscando alcances interpretativos que ultrapassem as práticas locais, seja via etnografias multisituadas (MARCUS, 1995), pela noção de redes sociotécnias (LATOUR, 2012), pelos modos e efeitos dos fluxos globais, em forma de paisagens (APPADURAI, 2004), ou ainda, pela ênfase na articulação, proposta por Strathern (2014), dos modos como os interlocutores em campo acionam escalas e contextos globalizados com as operações do antropólogo no processo de escrita etnográfica.

Não é o caso de afirmar a preeminência da disciplina antropológica em toda e qualquer investigação de dinâmicas urbanas. Não obstante o empreendimento etnográfico, na perspectiva apresentada, mostra-se como uma possível alternativa às armadilhas da violência epistêmica, expressa pela transposição acrítica de conceitos sem as mediações que se fazem necessárias. 


\section{Referências}

A LUTA de 40 anos pela implantação do Parque Augusta, Carta Capital, 28 jan. 2015. Disponível em: <https:// www.cartacapital.com.br/sociedade/a-luta-de-40-anos-pela-implantacao-do-parque-augusta-1521/>. Acesso em: 13 jan. 020.

APPADURAI, Arjun. “Disjunção e diferença na economia cultural global”, In: Dimensões culturais da globalização. Lisboa: Editorial Teorema, 2004.

ANGIOLILlO, Francesca. Na cabeça de Alê Youssef, SP é da turma bacana da noite do centro. Folha de São Paulo, São Paulo, 12 mar. 2019. Disponível em: <https://www1.folha.uol.com.br/ilustrada/2019/03/na-cabeca-deale-youssef-sp-e-da-turma-bacana-da-noite-do-centro.shtml>. Acesso em: 13 jan. 2020

ARRUDA, Marina Almeida Ferraz. A memória no resgate do passado: a rua Augusta em São Paulo. 2016. Dissertação (Mestrado em Cultura e Comunicação) - Faculdade de Letras, Universidade de Lisboa, Lisboa, 2016. BALLESTRIN, Luciana. América Latina e o giro decolonial. Revista Brasileira de Ciência Política, Brasília, n. 11, p.89-117, 2013.

BOTELHO, Tarcísio R. Revitalização de centros urbanos no Brasil: uma análise comparativa das experiências de Vitória, Fortaleza e São Luís. Revista Eure, Santiago do Chile, v. 31, n. 939, p. 53-71, ago. 2005.

CANEVACCI, Massimo. A cidade polifônica: ensaio sobre a antropologia da comunicação urbana. São Paulo: Studio Nobel, 1993.

CIDADE DE SÃO PAULO. Baixo Augusta. Disponível em <http://cidadedesaopaulo.com/v2/novidades/baixoaugusta/?lang=pt $>$. Acesso em: dezembro de 2019.

CONCLI, Raphael. Resistências e conflitos marcam a gentrificação em São Paulo. Agência Universitária de Notícias da USP, fev. 2018. Disponível em: <https://paineira.usp.br/aun/index.php/2018/02/07/resistencias-econflitos-marcam-a-gentrificacao-em-sao-paulo/>. Acesso em: 13 jan. 2020.

COSTA, Sérgio. Desprovincializando a sociologia: a contribuição pós-colonial. Revista Brasileira de Ciências Sociais, São Paulo, v. 21, n. 60, p. 117-134, 2006.

DINES, Yara Schreiber. Rua Augusta - Imaginários Urbanos em Diálogo. Ponto Urbe, São Paulo, n. 9, p. 1-11, 2011. FERNANDES, João Luís J. Cityscapes: símbolos, dinâmicas e apropriações da paisagem cultural urbana, Máthesis, Jandaia do Sul, Paraná, v. 18, p. 195-214, 2009.

FOUCAULT, Michel. As palavras e as coisas: uma arqueologia das ciências humanas. São Paulo: Martins Fontes, 1999. FRB. A nova cara da Augusta. Profissão Foca, jun. 2014. Disponível em <http://profissaofoca.com.br/a-nova-carada-augusta/>. Acesso em: 13 jan. 2020.

FREIRE, Vinícius Torres. O perfil socioeconômico da área central de São Paulo está em transformação? Folha de São Paulo, São Paulo, 02 jun. 2019. Disponível em <https://www1.folha.uol.com.br/sobretudo/morar/2019/06/1988021o-perfil-socioeconomico-da-area-central-de-sao-paulo-esta-em-transformacao.shtml>. Acesso em: 13 jan. 2020. FRÚGOLI JR. A questão da centralidade em São Paulo: o papel das associações de caráter empresarial. Revista Sociologia e Política, Curitiba, n. 16, p. 51-66, 2001.

FRÚGOLI JR., Heitor; SKLAIR, Jéssica. O bairro da Luz em São Paulo: questões antropológicas sobre o fenômeno da gentrification. Cuadernos de Antropología Social, Buenos Aires, n. 30, p. 119-136, 2009.

GASPAR, Samantha dos Santos. Gentrification: processo global, especificidades locais? Ponto Urbe, São Paulo, n. 6, p. 1-17, 2010.

GEERTZ, Clifford. A interpretação das culturas. Rio de Janeiro: LTC, 2008.

GIOVANELLI, Carolina. Baixo Augusta ganha novas baladas. Revista Veja, mai. 2011. Disponível em: <https:// vejasp.abril.com.br/cidades/novas-baladas-baixo-augusta/>. Acesso em: 13 jan. 2020. 
GLASS, Ruth. London: Aspects of Change. Londres: Macgibbon \& Kee, 1964.

HALL, Stuart. O ocidente e o resto: discurso e poder. Revista Projeto História, São Paulo, n. 56, p. 314-361, 2016. HIERNAUX-NICOLAS, Daniel. A reapropriação de bairros da Cidade do México pelas classes médias: em direção a uma gentrificação? In: BIDOU-ZACHARIANSEN, Catherine et al. De volta à cidade: dos processos de gentrificação às políticas de "revitalização" dos centros urbanos. São Paulo: Annablume, 2006. p. 229-264.

LATOUR, Bruno. Reagregando o social: uma introdução à teoria do ator-rede. Salvador: Edufba; Bauru: Edusc, 2012. LEITE, Rogério Proença. Contra-usos da cidade. São Paulo: Editora Unicamp, 2007.

MACHADO, Igor José de Rennó. Reflexões sobre o pós-colonialismo. Revista Teoria e Pesquisa, São Carlos, São Paulo, n. 44/45, p. 19-32, jan./jul., 2004.

MAGNANI, José Guilherme Cantor. De perto e de dentro: notas para uma etnografia urbana. Revista Brasileira de Ciências Sociais, São Paulo, v. 17, p. 11-29, 2002.

MAGNANI, José Guilherme Cantor. Os circuitos dos jovens urbanos. Tempo social, São Paulo, v. 17, n. 2, p. 173205, 2005.

MAGNANI, José Guilherme Cantor. Rua, símbolo e suporte da experiência urbana. Cadernos de História de São Paulo, São Paulo, v. 2, p. 1-14, 1993.

MARCUS, George E. Ethnography in/of the world system: the emergence of multisited ethnography. Annual Review of Anthropology, Palo Alto, Califórnia, n. 24, p. 95-117, 1995.

MELLO, Daniel. Iphan pede paralisação de construção do Parque Augusta. Site de notícias EBC, Brasília, jan. 2020. Disponível em: <http://agenciabrasil.ebc.com.br/geral/noticia/2020-01/iphan-pede-paralisacao-de-construcaodo-parque-augusta $>$. Acesso em: 13 jan. 2020.

MENDES, Ana Carolina Ferreira. Transformações recentes na paisagem construída na cidade de São Paulo. O eixo da Rua Augusta, do centro à marginal Pinheiros. 2014. Dissertação (Mestrado em Arquitetura e Urbanismo) Programa de Pós-Graduação em Arquitetura e Urbanismo, Universidade Presbiteriana Mackenzie, São Paulo, 2014. MIGNOLO, Walter. Colonialidade: o lado mais escuro da modernidade. Revista Brasileira Ciências Sociais, São Paulo, v. 32, n. 94, p. 1-18, jun. 2017.

MIRA, Maria Celeste. Entre a beleza do morto e a cultura viva: mediadores da cultura popular na São Paulo da virada do milênio. São Paulo: Intermeios/Fapesp, 2016.

MORETTI, Juliane. Casa noturna conhecida da Rua Augusta passa por reformulação. Revista Veja, jul. 2019. Disponível em: <https://vejasp.abril.com.br/blog/musica/beco-augusta-renovacao-rock/>. Acesso em: 13 jan. 2020. NADER, Laura. Ethnography as theory. HAU: Journal of ethnographic theory 1, Londres, n. 1, p. 211-219, 2011. PEIRANO, Mariza. A favor da etnografia. Rio de Janeiro: Dumará, 1995.

PEIRANO, Mariza. Etnografia não é método. Horizontes Antropológicos, Porto Alegre, v. 20, p. 377-391, 2014. PETIÇÃO pede o seu voto para a criação do Parque Augusta, Catraca Livre, 18 mai. 2016. Disponível em: https:// catracalivre.com.br/cidadania/peticao-pede-o-seu-voto-para-criacao-do-parque-augusta/. Acesso em: 13 jan. 2020. PISSARDO, Felipe Melo. A rua apropriada: um estudo sobre as transformações e usos urbanos na Rua Augusta (São Paulo, 1891-2012). 2013. Tese (Doutorado em Antropologia Social) - Programa de Pós-Graduação em Antropologia Social, Universidade de São Paulo, São Paulo, 2013.

Consolação. Proprietário direto. Disponível em: <www.proprietariodireto.com.br/>. Acesso em: 13 jan. 2020.

PUCCINELLI, Bruno. "Perfeito para você, no centro de São Paulo": mercado, conflitos urbanos e homossexualidades na produção da cidade. 2017. Tese (Doutorado em Antropologia Social) - Programa de PósGraduação em Antropologia Social, Universidade de Campinas, Campinas, 2017.

QUIJANO, Aníbal. Colonialidad del poder y clasificación social. Journal of world-systems research, Pittsburgh, v. 11, n. 2, p. 342-386, 2000. 
RAGAZZO, Cléber. Rua Augusta: a calçada da glória. São Paulo: Digerati, 2005.

ROCHA, Camilo. Dicionário prático para não se perder quando o assunto é a vida nas cidades. Jornal Nexo, São Paulo, dez. 2015. Disponível em: <https://www.nexojornal.com.br/expresso/2015/12/31/Dicion\%C3\%A1riopr\%C3\%A1tico-para-n\%C3\%A3o-se-perder-quando-o-assunto-\%C3\%A9-a-vida-nas-cidades>. Acesso em: 13 jan. 2020.

RUA AUGUSTA, Consolação. Dicionário de ruas. Disponível em <https://dicionarioderuas.prefeitura.sp.gov. br/>. Acesso em: 13 jan. 2020.

RUBINO, Silvana. Enobrecimento Urbano. In: FORTUNA, Carlos; LEITE, Rogério Proença (org.). Plural de Cidade: novos léxicos urbanos. Coimbra: Edições Almedina, 2009. p. 25-40.

COM ESPECULAÇÃO IMOBILIÁRIA, rua Augusta começa deixar fase “descolada”. Site de notícias R7, São Paulo, 23 dez. 2013. Disponível em: <http://noticias.r7.com/sao-paulo/fotos/com-especulacao-imobiliaria-rua-augustacomeca-deixar-fase-descolada-veja-as-transformacoes-23122013\#!/foto/1>. Acesso em: 20 mai. 2017.

SAMPAIO, Rafael. Vegas fecha e deve dar lugar a prédio na Rua Augusta, diz dono. G1, São Paulo, abr. 2012. Disponível em: <http://g1.globo.com/sao-paulo/noticia/2012/04/vegas-fecha-e-deve-dar-lugar-predio-na-ruaaugusta-diz-dono.html>. Acesso em: 13 jan. 2020.

SCOUGUGLIA, Jovanka B. C. Revitalização urbana e (re) invenção do centro histórico na cidade de João Pessoa (1987-2002). João Pessoa: Ed. Universitária / UFPB, 2004.

SMITH, Neil. The new urban frontier. Gentrification and the revanchist city. Londres / Nova York: Routledge, 2000 .

SPIVAK, Gayatri Chakravorty. Pode o subalterno falar? Belo Horizonte: Ed. UFMG, 2010.

STRATHERN, Marilyn. O Efeito etnográfico e outros ensaios. São Paulo: Cosac Naify, 2014.

STUDIO SP anuncia que encerra atividades neste mês de abril. G1, São Paulo, 14 abr. 2013. Disponível em: <http:// g1.globo.com/sao-paulo/noticia/2013/04/studio-sp-anuncia-que-encerra-atividades-neste-mes-de-abril.html >. Acesso em: 13 jan. 2020.

TRINDADE, Eleni. No caminho da Augusta. Famosa por seus bares e restaurantes, a região do entorno da rua vive expansão imobiliária. O Estado de São Paulo Online, São Paulo, 01 jul. 2011. Disponível em: <http://economia. estadao.com.br/noticias/negocios,no-caminho-da-augusta,74131e>. Acesso em: 20 mai. 2017.

VEGA, Alexandre Paulino. Estilos e marcadores sociais da diferença em contexto urbano: uma análise da desconstrução de diferenças entre jovens em São Paulo. 2008. Dissertação (Mestrado em Antropologia Social) Programa de Pós-Graduação em Antropologia Social, Universidade de São Paulo, São Paulo, 2008.

RUA AUGUSTA, em São Paulo, valoriza e atrai lançamentos imobiliários. Portal VGV, São Paulo, 20 jul. 2011. Disponível em: <http://www.portalvgv.com.br/site/rua-augusta-em-sao-paulo-valoriza-e-atrai-lancamentosimobiliarios/>. Acesso em: 09 mai. 2017.

YURI, Débora. Reocupação da região por jovens gera onda de aumento de preços. Folha de São Paulo, São Paulo, mai. 2016. Disponível em: <http://especial.folha.uol.com.br/2016/morar/paulista-centro/2016/05/1766342reocupacao-da-regiao-por-jovens-gera-onda-de-aumento-de-precos.shtml>. Acesso em: 20 mai. 2017.

ZUKIN, Sharon. Loft and living: culture and capital in urban change. New Brunswick: Rutgers University Press, 1989.

Recebido em 13/05/2020

Aceito em 30/09/2020 